\title{
Should we Recommend Stethoscope Disinfection Before Daily Usage as an Infection Control Rule?
}

\author{
A. Alothman ${ }^{*}, 1,3$, A. Bukhari ${ }^{1}$, S. Aljohani ${ }^{2}$ and A. Muhanaa ${ }^{2}$ \\ ${ }^{I}$ College of Medicine, KSAU-HS, Riyadh, Saudi Arabia \\ ${ }^{2}$ Pathology and Laboratory Medicine, Division of Microbiology, King Abdulaziz Medical City, Riyadh, Saudi Arabia \\ ${ }^{3}$ Department of Medicine, Infectious Diseases Division, King Abdulaziz Medical City, Riyadh, Saudi Arabia
}

\begin{abstract}
Background: Many studies have shown that contaminated medical equipments act like a vector for crossinfection. Infection control programmes are effective in decreasing hospital-acquired infection rate, however, the implementation of such programmes is hindered by poor compliance of health care workers.

Methods: Random selection of health care workers, at our institution, was given questionnaires and were asked to give their stethoscopes to be sampled.

Results: 151 health care workers were involved in this study. Physicians were 79/151 and their stethoscopes were found to be the most contaminated $(68.3 \%)$. The total number of contaminated stethoscopes was $72 / 151(47.7 \%)$. Coagulasenegative staphylococcus was isolated from 66 diaphragms from $72(92 \%)$.

Conclusion: Nosocomial infections carry a higher level of morbidity and mortality. This study showed that there is lack of good compliance with routinely disinfecting the health care workers stethoscopes. We recommend that the significance of disinfecting diaphragms of stethoscopes should be clarified to the health care workers.
\end{abstract}

Keywords: Infection control, stethoscopes, medical equipment, nosocomial infection.

\section{INTRODUCTION}

Stethoscope is the symbol of health professionals. Infection control programmes are significantly effective in reducing the nosocomial infection rates, however, the implementation of such programs is hindered by poor compliance of physicians, nurses, and other health workers $[1,2]$.

Different studies have shown that contaminated medical equipments have been shown in different studies to act like a vector for cross-infection [1, 3-6].

Nosocomial infections occur at a rate of 5-10 per 100 hospital admissions each year [7]. It was believed that contaminated medical equipments and health care staff have been implicated as vectors for the transmission of pathogenic organisms [3-6].

We studied the degree of contamination of diaphragms of stethoscopes at our institution.

\section{METHODS}

A questionnaire was distributed among health professionals before taking their stethoscopes and swabbing the diaphragm of the stethoscope using a sterile cotton swab moistened with a sterile normal saline. The samples were

*Address correspondence to this author at the Department of Medicine, Infectious Diseases Division, King Abdulaziz Medical City, P.O. Box 22490, Riyadh 11426, Saudi Arabia; Tel: +9661 2520088; Fax: +9661 2520088; E-mail: alothman84@hotmail.com incubated on a blood agar plate for 48 hours at $37^{\circ} \mathrm{C}$. The positive growths were subsequently identified using standard microbiological procedures. The collected samples and the given questionnaires were matched through serial numbers.

\section{RESULTS}

The total number of health care workers (HCWs) involved in the study was $151 \mathrm{HCWs}, 54.3 \%$ were females. Table 1 summarizes the profession of HCWs and the degree of contaminated stethoscopes.

There were 11 consultants and the degree of contamination was $82 \%$, and four of them were cardiologists. More than half of the residents $(66 \%)$ had contaminated stethoscopes.

Coagulase-negative staphylococcus was the most common organism identified in 72 contaminated diaphragms. Table 2 summarizes the isolated organisms and their percentages. There were 117 isolates from 72 contaminated stethoscopes diaphragms, indicating that some contaminated diaphragms had more than one organism.

The questionnaires filled by all HCWs showed that the subjects who answered that they never cleaned their stethoscopes were 18/151 (12\%), out of them 13 had contaminated diaphragms. The number of HCWs, who cleaned their stethoscopes less than twice a day was 76/151 $(50 \%)$, out of them 48 had contaminated diaphragms. However, 17/151 (11\%), HCWs cleaned their stethoscopes more than 6 times a day, two of which had contaminated diaphragms. 
Table 1. Professions of Health Care Workers and the Percentage of Contamination

\begin{tabular}{|l|c|c|}
\hline \multicolumn{1}{|c|}{ Health Care Workers } & Number & Contaminated (\%) \\
\hline \hline Physicians & 79 & $54(68.3 \%)$ \\
Consultants & 11 & $9(81.8 \%)$ \\
Residents & 47 & $31(65.9 \%)$ \\
$\quad$ Interns & 21 & $14(66.7 \%)$ \\
\hline Nurses & 51 & $11(21.5 \%)$ \\
\hline Respiratory therapists & 6 & $1(16.6 \%)$ \\
\hline Medical Students & 15 & $6(40 \%)$ \\
\hline Total & 151 & $72(47.7 \%)$ \\
\hline
\end{tabular}

Table 2. Organisms ISOLATED from 72 Contaminated Diaphragms

\begin{tabular}{|l|c|}
\hline \multicolumn{1}{|c|}{ Organism } & No. of Isolates/ 72 Diaphragms \\
\hline \hline Coagulase-negative staphylococcus & $66(91.6 \%)$ \\
\hline Micrococcus spp & 13 \\
\hline Alpha Hemolytic streptococcus & 3 \\
\hline S. aureus (MSSA) & 2 \\
\hline Diphtheroids & $20(27.7 \%)$ \\
\hline S. viridians & 5 \\
\hline Bacillus spp & 5 \\
\hline Enterococcus spp & 1 \\
\hline Acinetobacter baumannii & 1 \\
\hline Acinetobacter Iwoffi & 1 \\
\hline * Total* & 117 \\
\hline
\end{tabular}

\section{DISCUSSION}

Hospital-acquired infections occur at a rate up to 10 per 100 hospital admissions and have significant cost per year [7]. Many nosocomial infections have been demonstrated to be due to cross transmission [8]. Health professionals can act as vectors of transmitting nosocomial isolates among patients [1]. One of the medical equipments which is universally used by different HCWs in managing their patients is the stethoscope. However, despite the HCWs best intentions; they would work like vectors of transmitting nosocomial infections among patients using contaminated medical equipments like stethoscopes [1, 5, 6, 9-12].

Our hospital is a tertiary care center with 900 beds, and more than 3,000 health workers working here. Our study, demonstrated that nearly $48 \%$ of stethoscopes diaphragms were contaminated which is less than other studies [6]. However, we found that most of the HCWs, are not compliant with infection control regulations, which is to disinfect their stethoscopes diaphragms between patients, to the extent that more than $62 \%$ of studied HCWs cleaned their stethoscopes diaphragms less than two times a day. The method to disinfect the stethoscope diaphragm after usage is to clean it with alcohol swab few times. This was the most frequent method of disinfection at our hospital.
The fact that stethoscopes diaphragms can transmit nosocomial pathogens and can cause hospital-acquired infections, lead us to recommend that HCWs should be more educated about this fact and enforce compliance with infection control regulations.

\section{REFERENCES}

[1] Saloojee H, Steenhoff A. The health professional role in preventing nosocomial infections. Postgrad Med J 2001; 77: 16-9.

[2] Wenzel R. The economics of nosocomial infections. J Hosp Infect 1995; 31: 79-87.

[3] Whitehead E, Thompson J, Lewis D. Contamination and decontamination of Doppler probes. Ann R Coll Surg Engl 2006; 88: 479-81.

[4] Singh D, Kaur H, Gardener W, et al. Bacterial contamination of hospital pagers. Infect Control Hosp Epidemiol 2002; 23: 274-6.

[5] Wood M, Lund R, Stevenson K. Bacterial contamination of stethoscopes with antimicrobial diaphragm covers. Am J Infect Control 2007; 35: 263-6.

[6] Bernard L, Kereveur A, Durand D, et al. Bacterial contamination of hospital physicians stethoscopes. Infect Control Hosp Epidemiol 1999; 20: 626-8.

[7] Centers for Diseases Control and Prevention, Hospital Infections Program. National Nosocomial Infections Surveillance (NNIS) report, data summary from October 1986-April 1996; a report from the NNIS system. Am J Infect Control 1996; 24: 380-8.

[8] Weist K, Pollege K, Schulz I, et al. How many nosocomial infections are associated with cross-transmission? A perspective 
cohort study in a surgical intensive care unit. Infect Contol Hosp Epidemiol 2002; 23: 127-32.

[9] Sood P, Mishra B, Mandal A. Potential infection hazards of stethoscopes. J Indian Med Assoc 2000; 98: 368-70.

[10] Jones J, Hoerle D, Rickse R. Stethoscopes: a potential vector of infection? Ann Emerg Med 1995; 26: 296-9.
[11] Zuliani MME, Maldonado AF, Bercial ME, et al. Stethoscope: a friend or an enemy? Sao Paulo Med J 2002; 120: 13-5.

[12] Nunez S, Moreno A, Green K, et al. The stethoscopes in the emergency department: a vector of infection? Epidemiol Infect 2000; 124: 233-7.

(C) Alothman et al.; Licensee Bentham Open.

This is an open access article licensed under the terms of the Creative Commons Attribution Non-Commercial License (http://creativecommons.org/licenses/by$\mathrm{nc} / 3.0 /$ ) which permits unrestricted, non-commercial use, distribution and reproduction in any medium, provided the work is properly cited. 